\title{
Trefoil factor 3 is required for differentiation of thyroid follicular cells and acts as a context-dependent tumor suppressor
}

\author{
A. ABOLS $S^{1,2, *}$, K. DUCENA ${ }^{2}$, D. ANDREJEVA ${ }^{1}$, L. SADOVSKA ${ }^{1,2}$, E. ZANDBERGA ${ }^{1}$, J. VILMANIS ${ }^{3}$, Z. NARBUTS ${ }^{3}$, J. TARS ${ }^{4}$, J. EGLITIS ${ }^{4}$, V. PIRAGS ${ }^{2,3}$, \\ A. LINE ${ }^{1}$ \\ ${ }^{1}$ Latvian Biomedical Research and Study center, Ratsupites street 1, Riga, LV - 1067, Latvia; ${ }^{2}$ University of Latvia, Raina boulevard 19, Riga, \\ LV - 1586, Latvia; ${ }^{3}$ Pauls Stradins University Hospital, Pilsonu street 13, Riga, LV-1002, Latvia; ${ }^{4}$ Latvian Oncology Center, Riga Eastern Clinical \\ University Hospital, Hipokrata street 2, Riga, LV - 1038, Latvia
}

*Correspondence: arturs@biomed.lu.lv

Received March 9, 2015 / Accepted July 16, 2015

\begin{abstract}
Trefoil factor 3 (TFF3) is overexpressed in a variety of solid epithelial cancers, where it has been shown to promote migration, invasion, proliferation, survival and angiogenesis. On the contrary, in the majority of thyroid tumors, it is downregulated, yet its role in the development of thyroid cancer remains unknown. Here we show that TFF3 exhibits strong cytoplasmic staining of normal thyroid follicular cells and colloid and the staining is increased in hyperfunctioning thyroid nodules, while it is decreased in all thyroid cancers of follicular cell origin. By meta-analysis of gene expression datasets, we found that in the thyroid cancer, conversely to the breast cancer, the expression of TFF3 mRNA was downregulated by estrogen signaling and confirmed this by treating thyroid cancer cells with estradiol. Forced expression of TFF3 in anaplastic thyroid cancer cells resulted in decreased cell proliferation, clonal spheroid formation and entry into the $\mathrm{S}$ phase. Furthermore, it induced acquisition of epithelial-like cell morphology and expression of the differentiation markers of thyroid follicular cells and transcription factors implicated in the thyroid morphogenesis and function. Taken together, this study provides the first evidence that TFF3 may act as a tumor suppressor or an oncogene depending on the cellular context.
\end{abstract}

Key words: thyroid cancer, follicular cells, estrogen signaling

Trefoil factor 3 (TFF3) is a member of trefoil factor family consisting of three secreted low-molecular weight peptides that share overlapping functional properties and a structurally conserved trefoil domain composed of $42-43$ amino acids folded in a compact 3-loop structure [1]. According to the Oncomine data (Roth normal and Shyamsundar normal datasets), TFF3 is highly expressed in thyroid gland, intestines, respiratory tract, salivary gland, myometrium and cervix [2]. It is predominantly secreted by mucous-producing cells and has been shown to interact with mucins to increase the viscosity and elasticity of the mucous covering gastrointestinal tract [3;4]. TFF3 has an essential role in the maintenance and repair of the intestinal mucosa after the damage induced by various cytotoxic agents $[5 ; 6]$ and has been implicated the regulation of epithelial cell migration [7;8], cilliogenesis and differentiation of airway epithelial cells [9]. It has been shown to modulate intestinal permeability by upregulating tight junction associated proteins $\mathrm{ZO}-1$, occluding and claudin-1 in the
PI3K/Akt-dependent manner [10]. Moreover, it has also been found to be expressed in neurons and activated microglial cells and to elicit neuroprotective effects in experimental cerebral ischemia/reperfusion injury [11].

A growing body of evidence suggests that TFF3 has a crucial role in the development and progression of cancer. It has been found to be overexpressed at the mRNA and protein level in a variety of solid cancers including breast, gastric, prostate and colon cancer, and endometrial and hepatocellular carcinoma [12-15]. In these cancers TFF3 is oncogenic and has been shown to promote migration, invasion, proliferation, survival and angiogenesis [12;16;17]. Interestingly, in breast cancer, the expression of TFF3 is upregulated by estrogen [18], while in prostate cancer it is regulated by androgen receptor signaling [16]. Upregulation of TFF3 confers metastatic phenotype and correlates with a lower survival rate in gastric, breast and rectal cancer [19-21], whereas it seems to be associated with good prognosis in endometrial adenocarcinoma [15]. 
On the contrary, TFF3 is downregulated in a subset of thyroid cancers that are derived from follicular epithelial cells. Decreased expression of TFF3 mRNA in thyroid follicular carcinoma was first reported by Takano $\mathrm{T}$ et al [22] and this finding was subsequently reproduced by several groups in follicular, papillary and anaplastic carcinomas [23-26] and validated at protein level by an immunohistochemical study [27]. TFF3 mRNA is one of the most promising biomarkers for pre-operative diagnosis of thyroid cancer and the development of a biomarker assay based on the measuring of TFF3 mRNA level in thyroid aspirates is ongoing [28]. However, to the best of our knowledge, the functional role of TFF3 in the development of thyroid cancer has not been elucidated so far.

We hypothesized that TFF3 is required for the differentiation or normal function of thyroid follicular cells and its downregulation may contribute to thyroid tumorigenesis. Therefore, at first we analyzed the expression pattern of TFF3 in normal thyroid tissues and a variety of hyperfunctioning and malignant thyroid nodules by immunohistochemistry, compared its expression level in the thyroid and breast cancers by qRT-PCR and assessed its regulation by estrogen signaling in thyroid cancers. Next, we examined the effects of forced expression of TFF3 in an anaplastic thyroid carcinoma cell line $8305 \mathrm{C}$, where the expression of endogenous TFF3 is downregulated, and breast cancer cell line MCF7, where TFF3 has been shown to be oncogenic [12]. We show here that in the thyroid cancer, on the contrary to the breast cancer, TFF3 expression is downregulated in response to estradiol and the restoration of TFF3 expression decrease cell proliferation and spheroid formation capacity, and induces expression of thyroid differentiation markers.

\section{Patients and methods}

Patients and tissue specimens. A cohort of 105 consecutive patients with benign or malignant thyroid nodules undergoing total or partial thyroidectomy at the Latvian Oncology Centre and Pauls Stradins University Hospital during the period 2009-2010 was described previously [26]. This cohort included 61 patient with follicular adenoma (FA), 33 patients with papillary thyroid carcinoma (PTC), 5 - with medullar thyroid carcinoma (MTC), 3 - with anaplastic thyroid carcinoma (ATC) and 3 - with follicular thyroid carcinoma (FTC).

Paired breast cancer and adjacent normal tissue specimens were obtained from 33 breast cancer patients undergoing surgery in the Latvian Oncology Centre. The tissue specimens were macroscopically dissected by a histopathologist during surgery and stored in RNALater (Ambion, Life Technologies, CA, USA) at $-20^{\circ} \mathrm{C}$ till processing. Tissue sections were evaluated by an experienced pathologist, and the diagnosis was established according to standard histopathological criteria. One of the specimens was diagnosed as $\mathrm{ER}^{+} / \mathrm{PR}^{+} / \mathrm{HER} 2^{+}, 5$ as $\mathrm{ER}^{+} / \mathrm{PR}^{-} / \mathrm{HER} 2^{-}, 10$ as $\mathrm{ER}^{+} / \mathrm{PR}^{+} / \mathrm{HER} 2-, 5$ as $\mathrm{ER}^{+} / \mathrm{PR}^{-} / \mathrm{HER} 2-, 7$ as $\mathrm{ER} / \mathrm{PR} / \mathrm{HER} 2^{+}$and 5 as triple negative breast cancers.
The tissue specimens were collected after the patients' informed consent was obtained in accordance with the regulations of Ethics Committee of the Institute of Experimental and Clinical Medicine, University of Latvia.

Immunohistochemical analysis. Immunohistochemical staining of the Thyroid diseased tissue array (A401, ISU ABXIS, Seoul, Korea) and Thyroid cancer tissue array (A210, ISU ABXIS, Seoul, Korea) was performed according to the manufacturer's protocol. The tissue arrays where deparaffinized and rehydrated in xylene and ethanol followed by quenching of peroxidase. Epitope retrieval was performed by heating the slides in microwave for $15 \mathrm{~min}$ in $10 \mathrm{mM}$ sodium citrate buffer. Next, the tissue sections were incubated with anti-TFF3 antibody (ab57752, monoclonal, Abcam, Cambridge, UK) at the dilution 1:300 overnight at $+4^{\circ} \mathrm{C}$ and the antibody binding was detected with anti-mouse IgG secondary antibody conjugated with peroxidase (A2554, Sigma - Aldrich, MO, USA) at the dilution 1:50. Colorimetric detection was performed with DAB (Sigma - Aldrich, MO, USA) followed by counterstaining with hematoxylin. Further, the slides where dehydrated, cleared with xylene and coverslips were mounted with Canadian Balsam (Sigma - Aldrich, MO, USA).

Each tissue core was evaluated by assessing three parameters - the intensity of staining, the percentage of stained cells and the pattern of staining (cytoplasmic or follicular lumen). The intensity of immunoreactivity was scored as follows: negative -0 , weak staining -1 , intermediate staining -2 , strong staining -3 . The percent of stained cells was scored as follows: negative -0 , up to $25 \%-1$; up to $50 \%-2$, up to $75 \%-3$ and up to $100 \%-4$. For statistical analysis, the mean intensity and score of stained cells and $\pm \mathrm{SD}$ was calculated for each type of thyroid nodules.

Plasmid constructs. Human TFF3 cDNA (GeneBank accession number NM_003226) was amplified by PCR from normal thyroid tissue cDNA using the forward NheI-TFF3 F 5' - AGCTAGCATGAAGCGAGTCCTGAGCTGC - 3 and the reverse EcoRI-TFF3 R 5' - AGAATTCCTAAGAAGGTGCATTCTGCAAAGC - 3' primers. The obtained PCR product was digested with FastDigest EcoRI and NheI (Fermentas, Thermo Fisher Scientific, MA, USA) and cloned into the mammalian expression vector pIRESneo3 (Clontech Laboratories, CA, USA).

Cell culture and transfection. The human anaplastic thyroid carcinoma cell line $8305 \mathrm{C}$ and human mammary carcinoma cell line MCF7 were purchased from European Collection of Cell Cultures (ECACC, UK) and maintained according to the manufacturer's protocols. To generate stable TFF3-expressing 8305C and MCF7 cells, $1 \times 10^{5}$ cells were seeded in 24-well plate and transfected with pIRESneo3-TFF3 or empty pIRESneo3 vector as a control using TurboFect transfection reagent (Fermentas, Thermo Fisher Scientific, MA, USA). After 8 weeks of selection with G418 (Clontech Laboratories, CA, USA), stable transfectants were obtained and designated as 8305C-TFF3, 8305C-pIRES, MCF7-TFF3 and MCF7-pIRES, respectively. MCF7 cells were cultured 
in DMEM supplemented with GlutaMax (Gibco, Life Technologies, CA, USA), 10\% FBS (Gibco, Life Technologies, CA, USA), 1\% NEAA (non essential amino acid solution) (Sigma - Aldrich, MO, USA) and $800 \mu \mathrm{g} / \mathrm{ml}$ G418. 8305C cells were cultured in DMEM supplemented with GlutaMax, 10\% FBS, $1 \%$ NEAA and $500 \mu \mathrm{g} / \mathrm{ml} \mathrm{G} 418$.

For the growth curve analysis, the cells were seeded at a density $0.5 \times 10^{4}$ cells per well in 24 -well plates and cultured for 10 days. Triplicate wells were trypsinized and the cells were counted using hemocytometer every 24 hours.

For estradiol stimulation experiments, the $8305 \mathrm{C}$ cells were seeded at a density $1 \times 10^{6}$ cells per well in 6-well plates in triplicates in serum-free DMEM/F12 medium containing 1X B-27 supplement Minus AO (Life Technologies, Carlsbad, CA, USA), EGF (20ng/ml, R\&D Systems, MN, USA), bFGF (10ng/ml, R\&D Systems, MN, USA). After 48 hours the cells were treated with $10 \mathrm{pM}, 1 \mathrm{nM}, 100 \mathrm{nM}$ or $1 \mu \mathrm{M} \beta$-estradiol (Sigma Aldrich, St. Louis, MO) or $96 \%$ ethanol as a control for 72 hours.

Spheroid forming assay. For spheroid cultures, single-cell suspensions of 8305C-TFF3, 8305C-pIRES, MCF7-TFF3 and MCF7-pIRES cells were plated at a density $2 \times 10^{3}$ cells per $\mathrm{ml}$ in 96-well ultra-low attachment plates (Corning, NY, USA) in serum-free DMEM/F12 medium containing 1X B-27 supplement Minus AO, EGF (20ng/ml), bFGF (10ng/ml) and 1\% methylcellulose (Sigma-Aldrich, St. Louis, MO, USA). After 7 days in culture, the tumour spheroids containing at least 16 cells were counted under an inverted microscope.

Proliferation assay. Cell proliferation was assessed using Click-iT ${ }^{\oplus}$ EdU assay (C10424; Life Technologies, CA, USA) according to the manufacturer's protocol. Briefly, the cells were seeded at density $5 \times 10^{5}$ cells per well in 6 -well plate in triplicates, grown until $80-90 \%$ confluence and incubated with $30 \mu \mathrm{M}$ 5-ethynyl-2' -deoxyuridine for one hour. The cells were harvested and, after the fixation and permeabilization, stained with Alexa Fluor 647 azide. The DNA content was analyzed by flow cytometry on the BD FACSAria II cell sorter (BD Biosciences, CA, USA) using BD FACSDiva software (BD Biosciences, CA, USA).

RNA extraction, cDNA synthesis and qRT-PCR. Homogenization of tissue specimens, extraction of RNA, cDNA synthesis and quantification of TFF 3 mRNA expression in the tissues was performed as previously reported [26]. The total RNA from cell lines $\left(\sim 2 \times 10^{6}\right.$ cells $)$ was extracted by using mirVana $^{\text {TM }}$ PARIS kit (Ambion, Life Technologies, CA, USA) and treated with DNAse according to the manufacturer's instructions. cDNA was synthesized by random hexamer priming from $3 \mu \mathrm{g}$ of total RNA by using High-Capacity cDNA Reverse Transcription Kit (Applied Biosystems, Life Technologies, CA, USA). Quantitative RT-PCR was carried out using $2 \mu \mathrm{l}$ of 1:10 diluted cDNA reaction mixtures, ABSolute Blue ${ }^{\mathrm{TM}}$ SYBR green Low ROX (Thermo Fisher Scientific, MA, USA) on ABI7500 sequence detection system (Applied Biosystems, Life Technologies, CA, USA). The primer sequences and concentrations used for qRT-PCR are available upon request.
To normalize the expression data, a normalization factor was calculated for each cDNA from the expression values of two reference genes - POLR2A and PGK1 by using geNorm Win3.4 software. The reference genes were selected as the most stable among 7 commonly used housekeeping genes (GAPDH, ACTB, POLR2A, TUB3A, TBP, YWHAZ, PGK1). All reactions were carried out in triplicates.

Western Blot analysis. Protein was isolated simultaneously with the total RNA from $\sim 2 \times 10^{6}$ cells by using mirVana ${ }^{\mathrm{TM}}$ PARIS kit according to the manufacturer's instructions, precipitated with isopropanol and dissolved in $100 \mu \mathrm{l} 8 \mathrm{mM}$ Urea in $60 \mathrm{mM}$ Tris- $\mathrm{HCl}$ and 1\% SDS. Ten micrograms of total protein were applied per lane and separated by $10 \%$ SDS-PAGE. Proteins were electroblotted onto nitrocellulose membranes and stained with Ponceau S solution to ensure the normalisation control for protein loading. The membranes were destained, blocked with $5 \%(\mathrm{w} / \mathrm{v})$ fat-free milk and then incubated with the following primary antibodies: TFF3 (ab57752, monoclonal, Abcam, Cambridge, UK) (1:1000), E-cadherin (sc8426, monoclonal, Santa Cruz Biotechnology, TX, USA) (1:1000) and $\beta$-actin (ab8224, monoclonal, Abcam, Seoul, Korea) (1:2000). After washing, the membranes were incubated with peroxidase - conjugated goat anti-mouse secondary antibody (A2554, polyclonal, Sigma - Aldrich, MO, USA) (1:3000), washed and processed with ECL Select Western Blotting Detection Reagents (GE Healthcare, WI, USA) according to manufacturer's instructions.

Statistical analyses. All experiments were repeated at least twice and were performed in triplicates. For continuous variables, the data were analyzed using Student's unpaired twotailed $t$ test. The data are represented as mean \pm SD. $P<0.05$ was considered as statistically significant. For the TFF3 mRNA expression analysis in tissues, the data are represented as median with $25^{\text {th }}$ and $75^{\text {th }}$ percentiles and whiskers that represents minimum and maximum values.

For meta-analysis of thyroid cancer gene expression data sets, data were collected from publicly available microarray data sets in the Oncomine database. Gene expression values were $\log 2$-transformed, median centered per array, and SD normalized to one per array. Statistical analysis was done by using Student's two- tailed unpaired $t$ test.

The statistical analyses were performed with Genex (Multid, Sweden) and Graph- PadPrism 5 (GraphPad, USA).

\section{Results}

Expression of TFF3 mRNA in thyroid and breast cancers. In a previous study aiming to identify gene expression biomarkers that could discriminate malignant from benign thyroid nodules, we found that TFF3 mRNA expression was downregulated in 85\% (28/33) PTC cases, 67\% (2/3) FTC, $100 \%(3 / 3)$ ATC cases and in 66\% (40/61) benign nodules when compared to the adjacent normal tissue, while it was upregulated in $80 \%(4 / 5)$ MTC cases [26]. In order to compare the expression level of TFF3 in cancerous and normal thyroid 
A

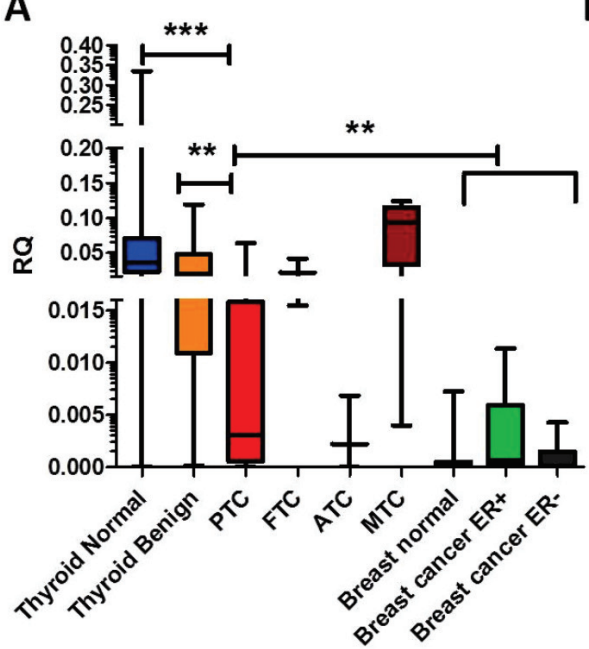

B

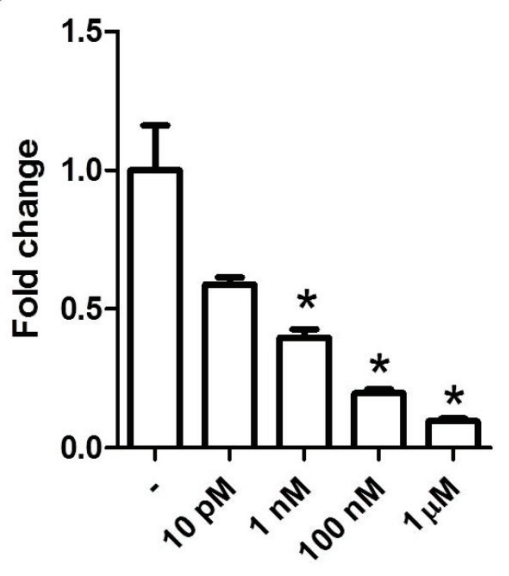

C

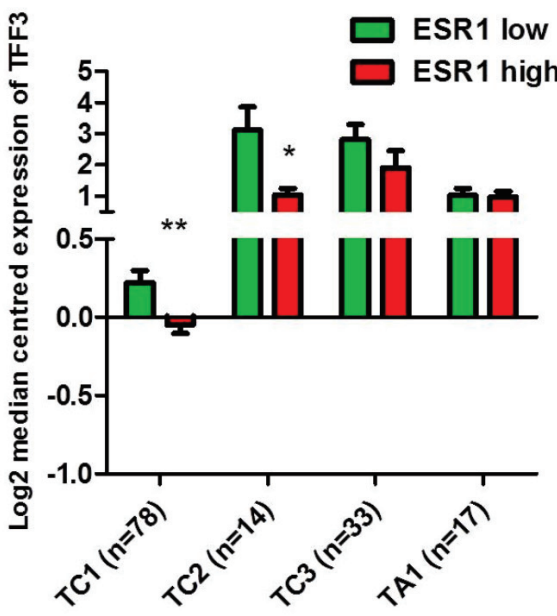

Figure 1. TFF3 mRNA expression levels in thyroid and breast cancer tissues and its regulation by $\beta$-estradiol. (A) qRT-PCR analysis of TFF3 mRNA expression level in thyroid cancer specimens (33 PTC, 3 FTC, 5 MTC, 3 ATC), 105 adjacent normal thyroid tissues, 61 benign nodule specimens, 12 ER- and 21 ER+ breast cancer specimens with corresponding normal breast tissues. Boxes represent the $25^{\text {th }}$ and $75^{\text {th }}$ percentiles; whiskers represent the minimum and maximum values. Statistical significance was calculated using Mann - Whitney U test. (B) qRT-PCR analysis of endogenous TFF3 mRNA level in $8305 \mathrm{C}$ cells treated with $10 \mathrm{pM}$ up to $1 \mu \mathrm{M} \beta$-estradiol for $72 \mathrm{~h}$. (C) Meta-analysis of TFF3 expression of three thyroid cancer microarray data sets available in Oncomine database. TC1 - dataset of Giordano Thyroid Cancer samples [29], TC2 - dataset of Vasko Thyroid Cancer samples [30], TC3 - dataset of Bittner Thyroid Cancer samples (unpublished), TA1 - dataset of Giordano Thyroid Adenoma samples [29]. Log-transformed, median-centered values were dichotomized according to ESR1 expression level. ${ }^{\star *} p<0,001,{ }^{\star * *} p<0,0001$.

tissues with that in breast cancer where it has been previously found to be overexpressed [12], its mRNA level was measured in 33 paired breast cancer and adjacent relatively normal tissue specimens by qRT-PCR (Fig. 1a). The results showed that in $\mathrm{ER}^{+}$breast cancers, the mean TFF3 mRNA level was 3.9-fold upregulated in comparison to the normal breast tissues, while no differences were found in ER cancers. Despite to the overexpression, in $\mathrm{ER}^{+}$cancers the mean TFF3 mRNA level was 4.5-fold lower than in papillary and follicular thyroid cancers and similar to that in ATC. TFF3 expression level in normal thyroid tissues was 70.6-fold higher than that in normal breast tissues. Expression of TFF3 mRNA is downregulated by estradiol in thyroid cancer. The expression of TFF3 has been shown to be induced by estradiol in estrogen-responsive cell lines [18]. Therefore, we examined the effect of estradiol on the expression of endogenous TFF3 in the $8305 \mathrm{C}$ cells. The cells were treated with $10 \mathrm{pM}-1 \mu \mathrm{M} \beta$-estradiol for 72 hours and the TFF3 mRNA expression was analyzed by qRT-PCR. The estradiol treatment decreased expression of TFF3 in the 8305C cells in a dose-dependent manner (Fig. 1b). To further clarify the relationship between the TFF3 expression and estrogen signaling in thyroid cancers, a meta-analysis of three thyroid cancer microarray data sets - Giordano Thyroid [29], Vasko Thyroid [30] and Bittner Thyroid (unpublished) available in the Oncomine database [2] was performed. Log-transformed intensity values of TFF3, ESR1 and ESR2 were median centered and scaled, and dichotomized according to the expression level of ESR1 or ESR2 and the median intensity values of TFF3 were compared in the groups with high vs low ESR1 and ESR2 expression. The data demonstrated an inverse correlation between TFF3 and ESR1 expression in follicular cell-derived cancers but not in the MTC and benign adenomas in Giordano and Vasko Thyroid data sets (Fig. 1c). No such correlation was found for TFF3 and ESR2 (data not shown). Immunohistochemical analysis of TFF3 expression in thyroid tissues. The immunohistochemical analysis of TFF3 expression was carried out using a tissue array comprising a total of 72 thyroid tissue specimens representing Graves' disease, granulomatous thyroiditis, Hashimoto thyroiditis, adenomatous hyperplasia, Hürthle cell adenoma, follicular adenoma, various thyroid cancers and normal thyroid tissues. The results are summarized in Table 1 and the representative IHC staining patterns are shown in Fig. 2. In line with the mRNA expression data, all normal tissue samples stained positive for TFF3 with the intensity score of at least 2 . TFF3 staining was localized mainly in follicular lumen and cytoplasm of follicular cells (Fig. 2a). Hyperfunctioning nodules such as Graves' disease (Fig. 2b) and toxic multinodular goiter exhibited very strong luminal staining, while in the euthyroid nodules, except for the MTC, the staining was weak or absent (Fig. 2 c-e). In all cases of PTC and FTC, most cells showed weak cytoplasmic staining, both ATC samples were negative for TFF3 expression, whereas MTC demonstrated strong cytoplasmic staining in most of the cells (Fig. 2f).

Forced expression of TFF3 in 8305C cells decreases cell proliferation and entry into $S$ phase. To investigate the func- 
Table 1. Immunohistochemical analysis of TFF3 expression in thyroid tissues

\begin{tabular}{lccc}
\hline Nodule type (number of specimens) & Mean intensity \pm SD & Main localization pattern & Mean score of stained cells \pm SD \\
\hline Graves' disease $(\mathrm{n}=5)$ & $3 \pm 0.44$ & Cytoplasm and follicular lumen & $4 \pm 0.44$ \\
Granulomatous thyroiditis $(\mathrm{n}=4)$ & $2 \pm 0.5$ & Cytoplasm and follicular lumen & $3 \pm 0.5$ \\
Hashimoto thyroiditis $(\mathrm{n}=6)$ & $2 \pm 1.16$ & Cytoplasm and follicular lumen & $2 \pm 1$ \\
Adenomatous hyperplasia $(\mathrm{n}=6)$ & $2 \pm 1.16$ & Cytoplasm and follicular lumen & $1.5 \pm 1$ \\
Hürthle cell adenoma $(\mathrm{n}=6)$ & $2 \pm 0.88$ & Cytoplasm & $4 \pm 0.83$ \\
Follicular adenoma $(\mathrm{n}=10)$ & $2 \pm 0.84$ & Cytoplasm and follicular lumen & $2.5 \pm 1.25$ \\
Non - neoplastic $(\mathrm{n}=8)$ & $2 \pm 0.53$ & Cytoplasm and follicular lumen & $2.5 \pm 1$ \\
PTC $(\mathrm{n}=11)$ & $1 \pm 0.64$ & Cytoplasm & $2 \pm 1.16$ \\
MTC $(\mathrm{n}=5)$ & $3 \pm 0$ & Cytoplasm & $4 \pm 0$ \\
FTC $(\mathrm{n}=5)$ & $1 \pm 0.7$ & Cytoplasm & $2 \pm 1$ \\
ATC $(\mathrm{n}=2)$ & $0 \pm 0$ & Not detected & $0 \pm 0$ \\
\hline
\end{tabular}

tional role of TFF3, human anaplastic thyroid cancer cell line 8305C and mammary carcinoma cell line MCF7 were stably transfected with TFF3 expression vector pIRESneo3-TFF3 or an empty pIRESneo3 vector as a control. The $8305 \mathrm{C}$ cells were selected due to low level of endogenous TFF3 expression,

Table 2. qRT-PCR analysis of gene expression ratio in $8305 \mathrm{C}-\mathrm{TFF} 3$ and 8305C- pIRES cells

\begin{tabular}{ccc}
\hline Target Name & Ratio (TFF3/pIRES) & P value \\
\hline TPO & 10.70 & 0.0275 \\
TSHR & 3.55 & 0.0562 \\
SLC5A5 & 6.72 & 0.0054 \\
THRB & 3.00 & 0.0064 \\
SLC26A4 & 2.25 & 0.0086 \\
TG & 0.38 & 0.0023 \\
\hline \multicolumn{3}{c}{ Transcription factors } \\
\hline FOXE1 & 24.05 & 0.0016 \\
WWTR1 & 44.20 & 0.001 \\
PAX8 & 0.91 & 0.0792 \\
NKX2-1 & ND & - \\
\hline CDH1 & 9.18 \\
FN1 & 0.87 & 0.0161 \\
\multicolumn{3}{c}{ Linage markers } \\
\hline ESR1 & 0.93 \\
ESR2 & 0.77 & 0.2835 \\
\hline \multicolumn{3}{c}{ Estrogen receptors } \\
\hline CCND1 & 1.13 & 0.0084 \\
CCNE1 & 0.49 & 0.0198 \\
CDK1 & 0.88 & 0.0003 \\
CDK2 & 0.73 & 0.4683 \\
CDK4 & 0.80 & 0.0134 \\
CDKNIB & 1.10 & 0.0789 \\
\hline Cell cycle \\
\hline
\end{tabular}

Average of three replicates represents fold change for each gene. A value above 1 indicates increased gene expression and value below 1 indicates decreased gene expression in 8305C-TFF3 cells relative to 8305C-pIRES. ND - expression is under detection limit. whereas MCF7 cells were selected as it has been previously reported that forced expression of TFF3 in these cells increased cell proliferation, survival and enhanced anchorage-independent growth [12]. Increased expression of TFF3 mRNA and protein in 8305C-TFF3 and MCF7-TFF3 cells relatively to the control cells was verified by qRT-PCR and Western blot analysis (Fig. 3 a, b).

The growth curve analysis showed that $8305 \mathrm{C}$-TFF3 cells had significantly decreased proliferation rate and/or increased cell death rate compared with the control cells (Fig. 3 c, d). Concordantly, EdU proliferation assay revealed that forced expression of TFF3 in $8305 \mathrm{C}$ cells reduced the number of cells in S- phase from $26.3 \%$ to $5.8 \%$ ( $\mathrm{p}=0.0053)$. At the same time, MCF7-TFF3 cells demonstrated increased proliferation rate and S-phase entry (Fig. 3 e) as this has been reported previously [12].

Next, the effect of forced TFF3 expression on invasion of 8305C cells was examined by transwell invasion assay QCM ECMatrix (Millipore, Merck, MA, USA) with $8 \mu \mathrm{m}$ pore inserts. After 48 hours of incubation using 10\% FBS as chemoattractant, no significant differences in the number of cells that have traversed the cell-permeable membrane were observed between the $8305 \mathrm{C}-\mathrm{TFF} 3$ and the control cells (data not shown).

Forced expression of TFF3 in 8305C cells reduces spheroid-forming ability. To assess the effect of TFF3 on the multicellular spheroid-forming ability, the 8305C-TFF3, MCF7-TFF3 and the respective control cells were plated at low density in methylcellulose-containing serum-free medium in ultra-low attachment plates. In these conditions, cells grew as non-adherent, 3D multicellular spheroids. Clonal origin of the spheroids was confirmed by co-culture of $\mathrm{DiD}$ and DiO-labelled cells (data not shown). This assay showed that $8305 \mathrm{C}$-TFF3 cells had significantly decreased number of spheroid-forming cells compared to the control cells $(\mathrm{p}=0.002)$, while the spheroid-forming ability of MCF7-TFF3 cells was significantly increased compared to MCF7-pIRES cells ( $\mathrm{p}=0.01)$ (Fig. $3 \mathrm{f}$ ).

Forced expression of TFF3 in $8305 \mathrm{C}$ cells induces differentiation. After transfection, we observed changes in the 
cell morphology in the TFF3 expressing 8305C cells (Fig. 3 g). The $8305 \mathrm{C}$-TFF3 cells had morphological features typical of epithelial cells, while 8305C-pIRES cells retained spindlelike cell morphology. Next, we analyzed the effects of forced TFF3 expression in 8305C cells on the expression of a panel of genes involved in the differentiation and normal function of thyroid tissues and regulation of proliferation by qRT-PCR (Table 2). In agreement with the decreased proliferation rate, the mRNA level of CCNE1 encoding G1/S-specific cyclin E1 was significantly decreased in $8305 \mathrm{C}-\mathrm{TFF} 3$ cells compared to $8305 \mathrm{C}$-pIRES cells. Concordantly with the epithelial-like morphology, 8305C-TFF3 cells had 9.2-fold higher expression of CDH1 encoding E-cadherin and slightly decreased expression of FN1 encoding fibronectin 1. Upregulation of E - cadherin was also confirmed at the protein level (Fig. $3 \mathrm{~b})$. At the same time, the expression of functional thyroid differentiation markers - TPO, TSHR, THRB, SLC26A4 and SLC5A5 were induced while TG was downregulated in the TFF3-expressing cells. Two of the transcription factors implicated in the control of transcription of these genes and thyroid morphogenesis - FOXE1 and WWTR1 were 24 to 44.2- fold upregulated, while NKX2-1 and PAX8 were expressed at low
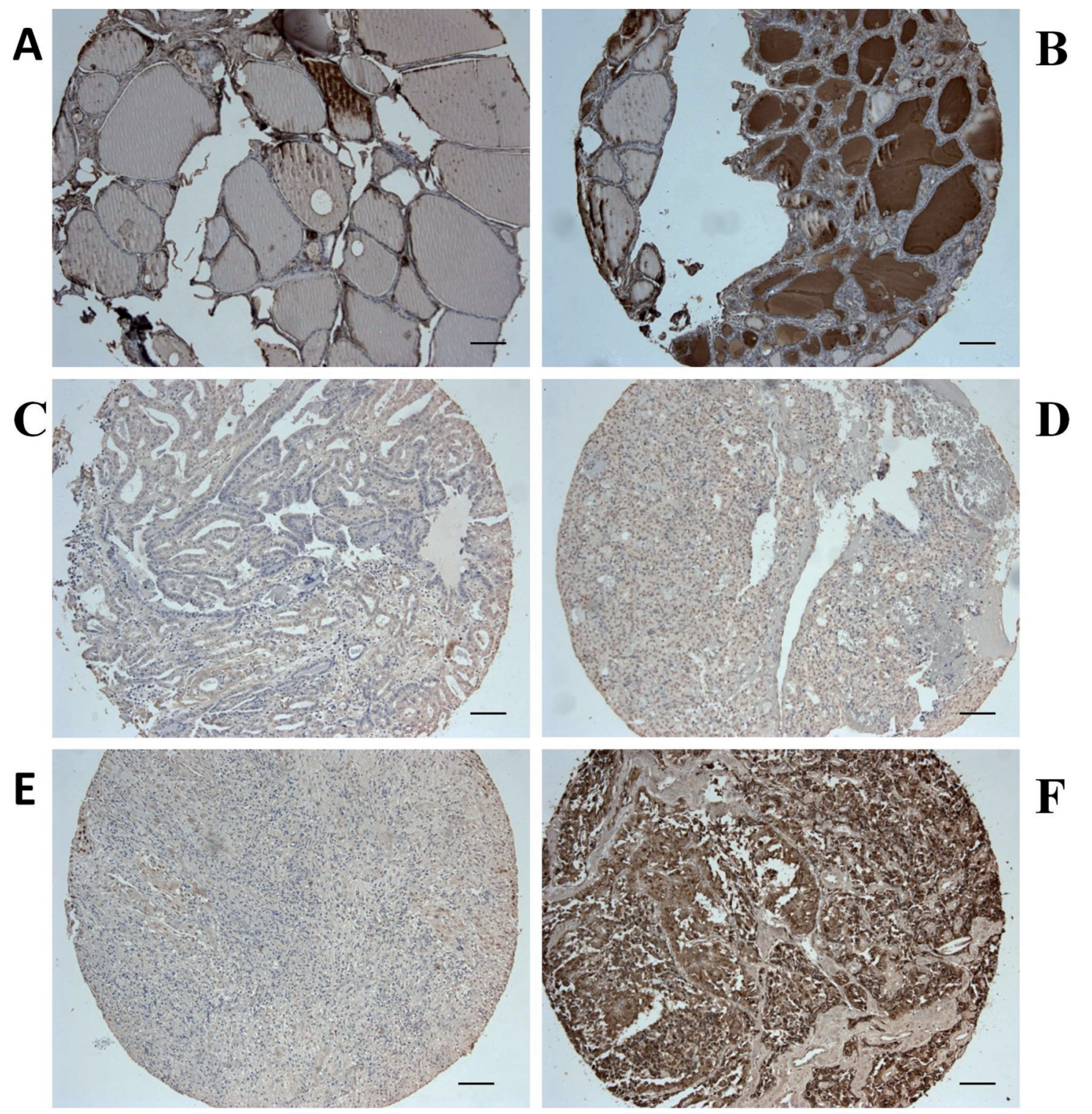

Figure 2. Immunohistochemical analysis of TFF3 expression in benign, inflammatory and malignant thyroid diseases and normal tissues. Representative examples demonstrate mean intensity scores and staining pattern in thyroid nodule types and non - neoplastic thyroid. (A) Normal thyroid specimen, (B) Graves' disease specimen, (C) Papillary thyroid cancer, (D) Follicular thyroid cancer, (E) Anaplastic thyroid cancer, (F) Medullar thyroid cancer. Black lines designate scale bars of $100 \mu \mathrm{m}$. 

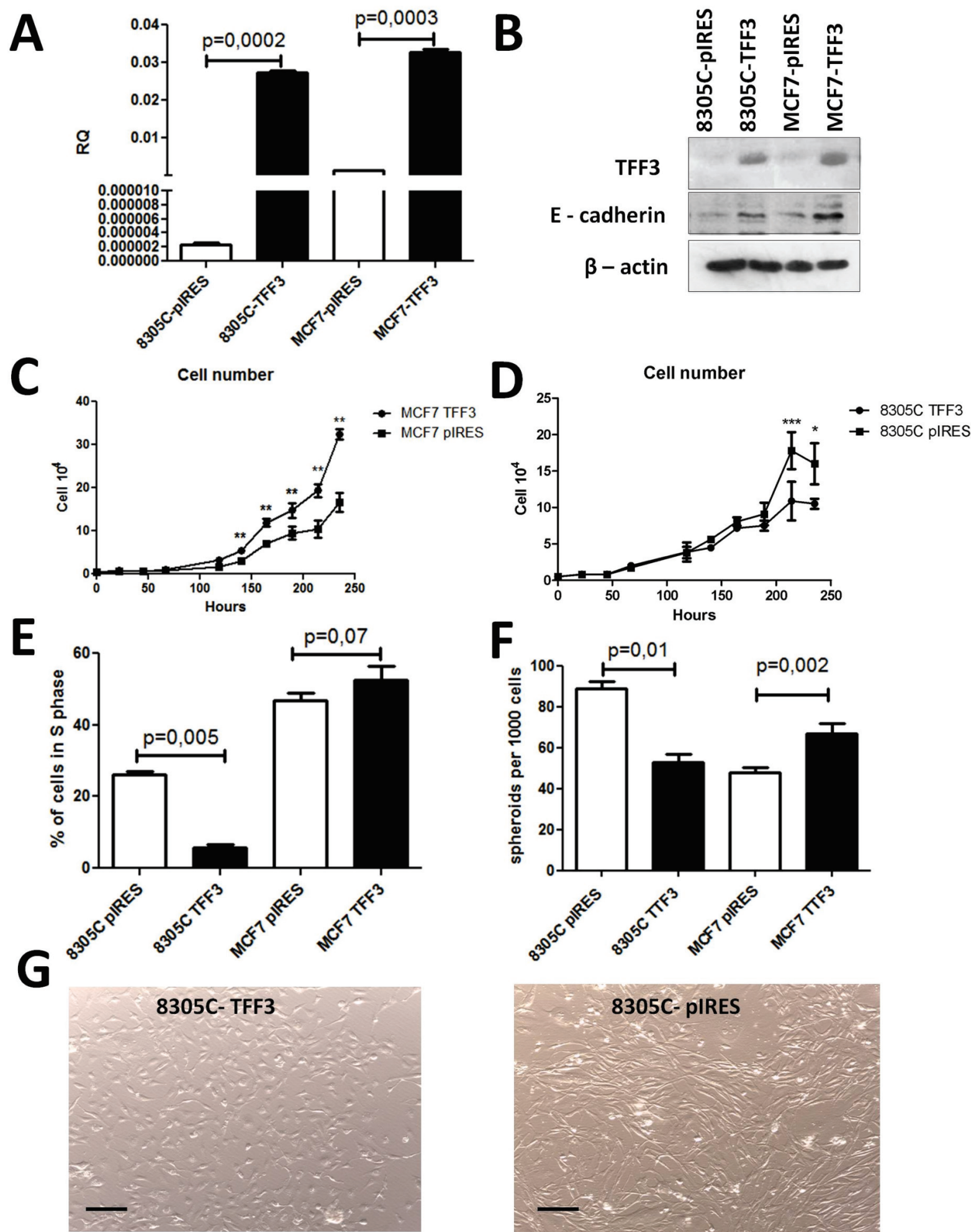

Figure 3. Forced expression of TFF3 affects the cell morphology and reduces proliferation and spheroid-forming ability. (A) Relative quantity (RQ) of TFF3 mRNA in 8305C-TFF3, 8305C-pIRES, MCF7-TFF3 and MCF7-pIRES cells. (B) Western blot analysis of TFF3 and E-cadherin in the cell lysates. $\beta$ actin was used as a loading control. (C) Growth curves for MCF7-TFF3 and MCF7-pIRES cells. (D) Growth curves for 8305C-TFF3 and 8305C-pIRES cells. (E) EdU proliferation assay in 8305C-TFF3, 8305C-pIRES, MCF7-TFF3 and MCF7-pIRES. (F) Spheroid formation assay of 8305C-TFF3, 8305CpIRES, MCF7-TFF3 and MCF7-pIRES cells (G) Representative images of morphological differences between 8305C- TFF3 and 8305C-pIRES cells. Black lines designate scale bars of $50 \mu \mathrm{m} .{ }^{* * *} p<0,0001,{ }^{* *} p<0,001,{ }^{*} p<0,01$. 
levels. The expression of ESR1 and ESR2 encoding estrogen receptors was not significantly alerted by TFF3.

\section{Discussion}

Although thyroid is the predominant site of TFF3 production and decreased TFF3 mRNA expression is well established biomarker of thyroid cancer, to the best of our knowledge, its role in the normal thyroid function and the development of thyroid malignancies had not been investigated so far. Immunohistochemical analysis of TFF3 in normal thyroid tissues revealed strong staining of follicle colloid that was increased in hyperfunctioning thyroid nodules thus suggesting that TFF3 may have a role in the processing of thyroid hormones, protecting the follicular surface from the damage by $\mathrm{H}_{2} \mathrm{O}_{2}$ or regulating the viscosity of the colloid. TFF3 mRNA and protein levels were decreased in all thyroid cancers derived from follicular cells, particularly in ATCs that were negative in IHC analysis, thus suggesting an association with decreased hormone production and/or differentiation of follicular cells. At the same time, TFF3 expression was increased in MTC that develops from parafollicular cells, which are of different embryonic origin than follicular cells [31]. The follicular cells originate from the endoderm, while parafollicular cells are believed to originate from the neural crest cells [32]. Hence, distinct expression pattern of TFF3 in these types of thyroid cancers further support a hypothesis that the role of TFF3 in tumourigenesis is strictly dependent on the cell type.

In breast cancer, the transcription of TFF3 has been shown to be stimulated by estradiol [18] and in line with this it was found to be overexpressed in $\mathrm{ER}^{+}$breast cancers and implicated in anti-estrogen resistance [12]. Here we confirm this finding and show that in thyroid cancer, on the contrary, TFF3 expression is downregulated by treatment with estradiol. Several lines of evidence indicate that estrogens contribute to the pathogenesis of thyroid cancer. The incidence of thyroid cancer is more than 5 -fold higher in women of reproductive age than in men, while the gender ratio declines after the menopause. The serum levels of estradiol were found to be significantly higher in women with differentiated thyroid cancer than in cancer-free controls [33]. Both, normal and malignant thyroid tissues express functional estrogen receptors, however cancers commonly gain ERa expression and lose ER $\beta$ expression that has been shown to stimulate their growth and is associated with a more aggressive phenotype [34;35]. Furthermore, a recent study demonstrated that estrogens stimulated growth and simultaneously inhibited the differentiation of thyroid stem/progenitor cells [36]. A meta-analysis of the gene expression data set revealed a strong inverse correlation of TFF3 and ESR1 expression but not ESR2 expression thus supporting the evidence that ESR1 signaling downregulates TFF3 expression in thyroid cancer. In prostate cancers with $E R G$ rearrangements resulting in the expression of transcription factor ERG under an androgenregulated promoter, TFF3 expression has been shown to be regulated by ERG [16]. The effect, however, was opposite in hormone-naïve and castration-resistant cancers - EGR had an inhibitory effect on TFF3 expression in hormone-naïve cancers while TFF3 was upregulated in castration-resistant state. This provides evidence that the expression of TFF3 is regulated by androgen receptor signaling in a cell contextdependent manner. Analysis of the TFF3 promoter region using MatInspector (Genomatix software suite) revealed the presence of two putative estrogen response elements at the positions 566-588 and 803-825 and the binding site for AHRARNT heterodimer at the position 886-910 upstream from the transcription start site. ARNT has been recently shown to act as a cell-type specific coactivator of ERa transcription complex in MCF7 cells and as a corepressor in ECC-1 endometrial carcinoma cells [37]. Hence we speculate that the differential regulation of TFF3 by estrogen signaling in various cells depends on a crosstalk between ERa and celltype specific transcription coactivators and corepressors such as ARNT.

Next, we show that the restoration of TFF3 expression in anaplastic thyroid cancer cell line with low level of endogenous TFF3, results in the decrease of cell proliferation and entry into the S-phase. Concordantly, a gene expression analysis revealed that CCNE1 encoding cyclin E1, which is required for cell cycle G1/S transition, was downregulated in TFF3-expressing cells. Furthermore, TFF3 expressing 8305C cells showed a reduced ability to form multicellular spheroids. Formation of clonal spheroids is a characteristic of cancer stem cells that has been shown to correlate with the tumorigenicity in vivo in various cancers, therefore this assay has been used both for the isolation of putative cancer stem cells and assessing their selfrenewal capacity [38-41]. A recent study of four ATC cell lines demonstrated that spheroid-forming cells expressed the stem cell markers NANOG and OCT4, were highly tumorigenic and metastasized more aggressively in than monolayer-derived cells in an orthotopic mouse model of thyroid carcinoma [42] . Hence, our study suggest that the restoration of TFF3 expression in the $8305 \mathrm{C}$ cells may induce differentiation of cancer stem cells and reduce their self-renewal capacity. In accordance with this, we observed that TFF3-expressing cells changed the cell morphology displaying features of epithelial cells and upregulated the expression of E-cadherin, a cell- cell adhesion molecule that is downregulated in the majority of thyroid cancers and has been shown to contribute to invasion and metastasis [43]. Furthermore, the gene expression analysis demonstrated that the forced TFF3 expression in $8305 \mathrm{C}$ cells induced the expression of a number of genes that are implicated in the regulation of thyroid gland function and are required for synthesis of the thyroid hormones $\mathrm{T}_{3}$ and $\mathrm{T}_{4}$. Thyroperoxidase (TPO) is a thyroid-specific enzyme required for iodination of tyrosine residues of thyroglobulin (TG). SLC5A5 encodes for the sodium-iodide symporter (NIS) required for uptake of iodide from the blood circulation and SLC26A4 encodes for pendrin mediating iodide efflux into the follicular lumen. TSHR encodes for the receptor for thyroid 
stimulating hormone - the primary physiological regulator of thyroid function, which is required for normal thyroid differentiation $[44 ; 45]$. THRB encodes for thyroid hormone receptor $\beta$, which has been recently shown to act as a tumor suppressor through downregulation of the AKT-mTOR-p70 S6K pathway [46]. In line with this, the dominant negative THRB mutant mice have been shown to develop spontaneous follicular thyroid carcinoma [47]. Furthermore, we show there that two of the transcription factors - FOXE1 and WWTR1 that are responsible for the expression of thyroid-specific genes and thyroid morphogenesis were significantly upregulated by TFF3 $[48 ; 49]$. These data strongly suggest that TFF3 is required for normal function of thyroid follicular cells and the forced expression of TFF3 in undifferentiated cancer cells at least partially restores the differentiated phenotype. This is in agreement with the study of Pierre LeSimple et al [9] showing that besides motogenic and antiapoptotic activity, TFF3 plays a major role in human airway epithelial regeneration by promoting ciliated cell differentiation.

Taken together, this study for the first time demonstrates that in thyroid cancer, on the contrary to the breast cancer, the expression of TFF3 is downregulated by estrogen receptor signaling and TFF3 is implicated the control of follicular cell differentiation and proliferation thus suggesting that its downregulation in thyroid tumors is not merely a consequence of the loss of normal function of follicular cells but contributes to the thyroid tumorigenesis. Hence, this study provides evidence that TFF3 may act as a tumor suppressor or an oncogene depending on the cellular context. We speculate, the dual nature of TFF3 in different cell types may be explained by formation of different protein complexes, different post-translational modifications or other regulatory mechanisms similarly as it has been demonstrated for orphan nuclear receptor Nur77, transcription factor KLF6 [50;51] and menin [52]. For instance, inactivation of menin is associated with heritable and sporadic endocrine cancers, whereas it also has been shown to be critically required for the formation of macromolecular complex containing proto-oncogene MLL that participates in Hox gene expression and pathogenesis of leukemia [52]. Furthermore, this study suggests that estrogen - TFF3 signaling pathway could represent a novel therapeutic target for the treatment of anaplastic thyroid cancer.

Acknowledgments: This study was supported in parts from ESF grant No. 2013/0023/1DP/1.1.1.2.0/13/APIA/VIAA/037, Latvian Council of Science grant No. 09.1310 and the Latvian National Research Programme BIOMEDICINE.

\section{References}

[1] THIM L, MAY FE: Structure of mammalian trefoil factors and functional insights. Cell Mol Life Sci 2005; 62: 2956-2973. http://dx.doi.org/10.1007/s00018-005-5484-6

[2] ONCOMINE. https: //www.oncomine.org (accessed February 20, 2014).: 2014.
[3] MADSEN J, NIELSEN O, TORNOE I, THIM L, HOLMSKOV U: Tissue localization of human trefoil factors 1, 2, and 3. J Histochem Cytochem 2007; 55: 505-513. http:// dx.doi.org/10.1369/jhc.6A7100.2007

[4] THIM L, MADSEN F, POULSEN SS: Effect of trefoil factors on the viscoelastic properties of mucus gels. Eur J Clin Invest 2002; 32: 519-527. http://dx.doi.org/10.1046/j.1365-2362 2002.01014.x

[5] MASHIMO H, WU DC, PODOLSKY DK, FISHMAN MC: Impaired defense of intestinal mucosa in mice lacking intestinal trefoil factor. Science 1996; 274: 262-265. http://dx.doi. org/10.1126/science.274.5285.262

[6] BECK PL, WONG JF, LI Y, SWAMINATHAN S, XAVIER RJ, et. al: Chemotherapy- and radiotherapy-induced intestinal damage is regulated by intestinal trefoil factor. Gastroenterology 2004; 126: 796-808. http://dx.doi.org/10.1053/j. gastro.2003.12.004

[7] BUDA A, JEPSON MA, PIGNATELLI M: Regulatory function of trefoil peptides (TFF) on intestinal cell junctional complexes. Cell Commun Adhes 2012; 19: 63-68. http:// dx.doi.org/10.3109/15419061.2012.748326

[8] JIANG GX, ZHONG XY, CUI YF, LIU W, TAI S, et al: IL-6/ STAT3/TFF3 signaling regulates human biliary epithelial cell migration and wound healing in vitro. Mol Biol Rep 2010; 37: 3813-3818. http://dx.doi.org/10.1007/s11033-010-0036-Z

[9] LESIMPLE P, VAN S, I, BUISINE MP, COPIN MC, HINZ M, et al: Trefoil factor family 3 peptide promotes human airway epithelial ciliated cell differentiation. Am J Respir Cell Mol Biol 2007; 36: 296-303. http://dx.doi.org/10.1165/rcmb.2006$\underline{02700 \mathrm{C}}$

[10] LIN N, XU LF, SUN M: The protective effect of trefoil factor 3 on the intestinal tight junction barrier is mediated by toll-like receptor 2 via a PI3K/Akt dependent mechanism. Biochem Biophys Res Commun 2013; 440: 143-149. http:// dx.doi.org/10.1016/j.bbrc.2013.09.049

[11] FU T, STELLMACHER A, ZNALESNIAK EB, DIETERICH DC, KALBACHER H, et. al: Tff3 is Expressed in Neurons and Microglial Cells. Cell Physiol Biochem 2014; 34: 1912-1919. http://dx.doi.org/10.1159/000366389

[12] KANNAN N, KANG J, KONG X, TANG J, PERRY JK, et al: Trefoil factor 3 is oncogenic and mediates anti-estrogen resistance in human mammary carcinoma. Neoplasia 2010; 12: 1041-1053. http://dx.doi.org/10.1593/neo.10916

[13] XU CC, YUE L, WEI HJ, ZHAO WW, SUI AH, WANG XM, QIU WS: Significance of TFF3 protein and Her-2/ neu status in patients with gastric adenocarcinoma. Pathol Res Pract 2013; 209: 479-485. http://dx.doi.org/10.1016/j. prp.2013.04.017

[14] VESTERGAARD EM, NEXO E, TORRING N, BORRE M, ORNTOFT TF, et al: Promoter hypomethylation and upregulation of trefoil factors in prostate cancer. Int J Cancer 2010; 127: 1857-1865. http://dx.doi.org/10.1002/ijc.25209

[15] MHAWECH-FAUCEGLIA P, WANG D, SAMRAO D, LIU S, DUPONT NC, et al: Trefoil factor family 3 (TFF3) expression and its interaction with estrogen receptor (ER) in endometrial adenocarcinoma. Gynecol Oncol 2013; 130: 174-180. http:// dx.doi.org/10.1016/j.ygyno.2013.03.030 
[16] RICKMAN DS, CHEN YB, BANERJEE S, PAN Y, YU J, V et al: ERG cooperates with androgen receptor in regulating trefoil factor 3 in prostate cancer disease progression. Neoplasia 2010; 12: 1031-1040. http://dx.doi.org/10.1593/neo.10866

[17] RIVAT C, RODRIGUES S, BRUYNEEL E, PIETU G, ROBERT A, et al: Implication of STAT3 signaling in human colonic cancer cells during intestinal trefoil factor 3 (TFF3) -- and vascular endothelial growth factor-mediated cellular invasion and tumor growth. Cancer Res 2005; 65: 195-202.

[18] MAY FE, WESTLEY BR: Expression of human intestinal trefoil factor in malignant cells and its regulation by oestrogen in breast cancer cells. J Pathol 1997; 182: 404-413. http://dx.doi. org/10.1002/(SICI)1096-9896(199708)182:4<404::AIDPATH875>3.0.CO;2-0

[19] DHAR DK, WANG TC, TABARA H, TONOMOTO Y, MARUYAMA R, et al: Expression of trefoil factor family members correlates with patient prognosis and neoangiogenesis. Clin Cancer Res 2005; 11: 6472-6478. http://dx.doi. org/10.1158/1078-0432.CCR-05-0671

[20] CASADO E, GARCIA VM, SANCHEZ JJ, GOMEZ DEL PULGAR MT, FELIU J, et al: Upregulation of trefoil factor 3 (TFF3) after rectal cancer chemoradiotherapy is an adverse prognostic factor and a potential therapeutic target. Int J Radiat Oncol Biol Phys 2012; 84: 1151-1158. http://dx.doi. org/10.1016/j.ijrobp.2012.01.083

[21] AHMED AR, GRIFFITHS AB, TILBY MT, WESTLEY BR, MAY FE: TFF3 is a normal breast epithelial protein and is associated with differentiated phenotype in early breast cancer but predisposes to invasion and metastasis in advanced disease. Am J Pathol 2012; 180: 904-916. http://dx.doi. org/10.1016/j.ajpath.2011.11.022

[22] TAKANO T, MIYAUCHI A, YOSHIDA H, KUMA K, AMINO N: High-throughput differential screening of mRNAs by serial analysis of gene expression: decreased expression of trefoil factor 3 mRNA in thyroid follicular carcinomas. Br J Cancer 2004; 90: 1600-1605. http://dx.doi.org/10.1038/ sj.bjc. 6601702

[23] TAKANO T, MIYAUCHI A, YOSHIDA H, KUMA K, AMINO N: Decreased relative expression level of trefoil factor 3 mRNA to galectin-3 mRNA distinguishes thyroid follicular carcinoma from adenoma. Cancer Lett 2005; 219: 91-96. http://dx.doi.org/10.1016/j.canlet.2004.07.004

[24] KRAUSE K, ESZLINGER M, GIMM O, KARGER S, ENGELHARDT C, et al: TFF3-based candidate gene discrimination of benign and malignant thyroid tumors in a region with borderline iodine deficiency. J Clin Endocrinol Metab 2008; 93: 1390-1393. http://dx.doi.org/10.1210/jc.2006-1255

[25] FOUKAKIS T, GUSNANTO A, AU AY, HOOG A, LUI WO, et al: A PCR-based expression signature of malignancy in follicular thyroid tumors. Endocr Relat Cancer 2007; 14: 381-391. http://dx.doi.org/10.1677/ERC-06-0023

[26] DUCENA K, ABOLS A, VILMANIS J, NARBUTS Z, TARS J,et al: Validity of multiplex biomarker model of 6 genes for the differential diagnosis of thyroid nodules. Thyroid Res 2011; 4: 11. http://dx.doi.org/10.1186/1756-6614-4-11

[27] PATEL MR, BRYSON PC, SHORES CG, HART CF, THORNE LB,et al: Trefoil factor 3 immunohistochemical characteriza- tion of follicular thyroid lesions from tissue microarray. Arch Otolaryngol Head Neck Surg 2009; 135: 590-596. http:// dx.doi.org/10.1001/archoto.2009.54

[28] YAMADA H, TAKANO T, KIHARA M, HIROKAWA M, YOSHIDA H,et al: Measurement of TFF3 mRNA in aspirates from thyroid nodules using mesh filtration: the first clinical trial in 130 cases. Endocr J 2012; 59: 621-630. http://dx.doi. org/10.1507/endocrj.EJ12-0077

[29] GIORDANO TJ, AU AY, KUICK R, THOMAS DG, RHODES DR,et al: Delineation, functional validation, and bioinformatic evaluation of gene expression in thyroid follicular carcinomas with the PAX8-PPARG translocation. Clin Cancer Res 2006; 12: 1983-1993. http://dx.doi.org/10.1158/1078-0432.CCR05-2039

[30] VASKO V, ESPINOSA AV, SCOUTEN W, HE H, AUER H,et al: Gene expression and functional evidence of epithelialto-mesenchymal transition in papillary thyroid carcinoma invasion. Proc Natl Acad Sci U S A 2007; 104: 2803-2808. http://dx.doi.org/10.1073/pnas.0610733104

[31] HOYES AD, KERSHAW DR: Anatomy and development of the thyroid gland. Ear Nose Throat J 1985; 64: 318-333.

[32] ADAMS MS, BRONNER-FRASER M: Review: the role of neural crest cells in the endocrine system. Endocr Pathol 2009; 20: 92-100. http://dx.doi.org/10.1007/s12022-009-9070-6

[33] PRZYBYLIK-MAZUREK E, HUBALEWSKA-DYDEJCZYK A, FEDOROWICZ A, PACH D: Factors connected with the female sex seem to play an important role in differentiated thyroid cancer. Gynecol Endocrinol 2012; 28: 150-155. http:// dx.doi.org/10.3109/09513590.2011.563909

[34] MAGRI F, CAPELLI V, ROTONDI M, LEPORATI P, LA $\mathrm{ML}$, et al: Expression of estrogen and androgen receptors in differentiated thyroid cancer: an additional criterion to assess the patient's risk. Endocr Relat Cancer 2012; 19: 463-471. http://dx.doi.org/10.1530/ERC-11-0389

[35] DI VM, DE SE, PERRONE GA, MARI E, GIORDANO $\mathrm{MC}$, et al: Overexpression of estrogen receptor-alpha in human papillary thyroid carcinomas studied by laser- capture microdissection and molecular biology. Cancer Sci 2011; 102: 1921-1927. http://dx.doi.org/10.1111/j.1349-7006 $.2011 .02017 . \mathrm{x}$

[36] XU S, CHEN G, PENG W, RENKO K, DERWAHL M: Oestrogen action on thyroid progenitor cells: relevant for the pathogenesis of thyroid nodules? J Endocrinol 2013; 218: 125-133. http://dx.doi.org/10.1530/JOE-13-0029

[37] LABRECQUE MP, TAKHAR MK, HOLLINGSHEAD BD, PREFONTAINE GG, PERDEW GH, et al: Distinct roles for aryl hydrocarbon receptor nuclear translocator and ah receptor in estrogen-mediated signaling in human cancer cell lines. PLoS One 2012; 7: e29545. http://dx.doi.org/10.1371/journal. pone.0029545

[38] ERAMO A, LOTTI F, SETTE G, PILOZZI E, BIFFONI M, et al: Identification and expansion of the tumorigenic lung cancer stem cell population. Cell Death Differ 2008; 15: 504-514. http://dx.doi.org/10.1038/sj.cdd.4402283

[39] IVANOVA L, ZANDBERGA E, SILINA K, KALNINA Z, ABOLS A, et al: Prognostic relevance of carbonic anhydrase IX expression is distinct in various subtypes of breast cancer 
and its silencing suppresses self-renewal capacity of breast cancer cells. Cancer Chemother Pharmacol 2015; 75: 235-246. http://dx.doi.org/10.1007/s00280-014-2635-1

[40] SALERNO M, AVNET S, BONUCCELLI G, ERAMO A, DE MR, G et al: Sphere-forming cell subsets with cancer stem cell properties in human musculoskeletal sarcomas. Int J Oncol 2013; 43: 95-102. http://dx.doi.org/10.3892/ijo.2013.1927

[41] YAN HC, FANG LS, XU J, QIU YY, LIN XM, et al: The identification of the biological characteristics of human ovarian cancer stem cells. Eur Rev Med Pharmacol Sci 2014; 18: 3497-3503.

[42] LI W, REEB AN, SEWELL WA, ELHOMSY G, LIN RY: Phenotypic characterization of metastatic anaplastic thyroid cancer stem cells. PLoS One 2013; 8: e65095. http://dx.doi. org/10.1371/journal.pone.0065095

[43] ROCHA AS, SOARES P, FONSECA E, CAMESELLETEIJEIRO J, OLIVEIRA MC, et al: E-cadherin loss rather than beta-catenin alterations is a common feature of poorly differentiated thyroid carcinomas. Histopathology 2003; 42: 580-587. http://dx.doi.org/10.1046/j.1365-2559 $.2003 .01642 . \mathrm{x}$

[44] OPITZ R, MAQUET E, ZOENEN M, DADHICH R, COSTAGLIOLA S: TSH receptor function is required for normal thyroid differentiation in zebrafish. Mol Endocrinol 2011; 25: 1579-1599. http://dx.doi.org/10.1210/me.2011-0046

[45] LIN RY, KUBO A, KELLER GM, DAVIES TF: Committing embryonic stem cells to differentiate into thyrocyte-like cells in vitro. Endocrinology 2003; 144: 2644-2649. http://dx.doi. org/10.1210/en.2002-0122
[46] KIM WG, ZHAO L, KIM DW, WILLINGHAM MC, CHENG SY: Inhibition of Tumorigenesis by the Thyroid Hormone Receptor beta in Xenograft Models. Thyroid 2014; 24: 260-269. http://dx.doi.org/10.1089/thy.2013.0054

[47] ZHAO L, ZHU X, WON PJ, FOZZATTI L, WILLINGHAM $\mathrm{M}$, et al: Role of TSH in the spontaneous development of asymmetrical thyroid carcinoma in mice with a targeted mutation in a single allele of the thyroid hormone-beta receptor. Endocrinology 2012; 153: 5090-5100. http://dx.doi. org/10.1210/en.2012-1600

[48] DI PT, D'ANDREA B, LIGUORI GL, LIGUORO A, DE CT, et al: TAZ is a coactivator for Pax8 and TTF-1, two transcription factors involved in thyroid differentiation. Exp Cell Res 2009; 315: 162-175.

[49] KIMURA S: Thyroid-specific transcription factors and their roles in thyroid cancer. J Thyroid Res 2011; 2011: 710213.

[50] NIU G, LU L, GAN J, ZHANG D, LIU J, et al: Dual roles of orphan nuclear receptor TR3/Nur77/NGFI-B in mediating cell survival and apoptosis. Int Rev Cell Mol Biol 2014; 313: 219258. http://dx.doi.org/10.1016/B978-0-12-800177-6.00007-4

[51] TRUCCO LD, ANDREOLI V, NUNEZ NG, MACCIONI M, BOCCO JL: Kruppel-like factor 6 interferes with cellular transformation induced by the $\mathrm{H}$-ras oncogene. FASEB J 2014; 28: 5262-5276. http://dx.doi.org/10.1096/f.14-251884

[52] YOKOYAMA A, SOMERVAILLE TC, SMITH KS, ROZENBLATT-ROSEN O, MEYERSON M, et al: The menin tumor suppressor protein is an essential oncogenic cofactor for MLL-associated leukemogenesis. Cell 2005; 123: 207-218. http://dx.doi.org/10.1016/j.cell.2005.09.025 